\title{
PRACTICE GUIDELINES AS LEGAL STANDARDS GOVERNING PHYSICIAN LIABILITY
}

\author{
Clark C. Havighurst*
}

\section{INTRODUCTION}

Practice guidelines-systematic, scientifically derived statements of appropriate measures to be taken by physicians in the diagnosis and treatment of disease-are widely viewed as a potential panacea for many of the health care industry's most pressing problems.' In addition to helping physicians obtain better medical results for their patients, practice guidelines are expected to give public and private financers of health services better tools with which to resist paying for, and thus discourage, inappropriate care. They are also being viewed hopefully as a way to ameliorate the problems associated with the law governing medical malpractice. In addition to reducing both the number of iatrogenic injuries that might become the subject of malpractice litigation ${ }^{2}$ and the pressure on physicians to practice defensive medicine, ${ }^{3}$ the availability of practice guidelines should somewhat

Copyright (C) 1991 by Law and Contemporary Problems

* William Neal Reynolds Professor of Law, Duke University.

1. See generally Institute of Medicine, Clinical Practice Guidelines: Directions for a New Program (Nat'l Acad Press, 1990) (edited by Marilyn Field \& Kathleen Lohr); Am Med Ass'n, Legal Implications of Practice Parameters (1990); Physician Payment Review Comm'n, 1989 Annual Report to Congress 219-36 (recommending federal support for effectiveness research and development of practice guidelines); Clark Havighurst, Practice Guidelines for Medical Care: The Policy Rationale, 34 St Louis U LJ 777 (1990); Symposium, Getting It Right: The Making of Practice Guidelines, Quality Rev Bull 40 (February 1990); David Eddy, Clinical Decision Making: From Theory to Practice (pts 1-4), $263 \mathrm{~J}$ Am Med Ass'n 287, 441, 887, 1265 (1990); Robert Brook, Practice Guidelines and Practicing Medicine: Are They Compatible?, $262 \mathrm{~J}$ Am Med Ass'n 3027 (1989); Richard Leahy, Rational Health Policy and the Legal Standard of Care: A Call for Judicial Deference to Practice Guidelines, 77 Cal L Rev 1483 (1989); Eleanor Kinney \& Marilyn Wilder, Medical Standard Setting in the Current Malpractice Environment, 22 UC Davis L. Rev 421 (1989); William Roper, et al, Effectiveness in Health Care: An Initiative to Evaluate and Improve Health Care, 319 New Eng J Med 1197 (1988) (proposal by officials of the Health Care Financing Administration).

2. A recent major study of the incidence of adverse events, negligence, and patient injury in hospital care found iatrogenic injuries in $3.7 \%$ of hospitalizations; over one-fourth of these were attributed to negligence. Harvard Medical Practice Study, Patients, Doctors, and Lawyers: Medical Injury, Malpractice Litigation, and Patient Compensation in New York 2-6, ch 6 (1990) ("Patients, Doctors, and Lawyers"). Practice guidelines are intended to improve the quality of patient care as measured by such outcomes. Credit for recent reductions of anesthesia-related injuries is given to the implementation of practice guidelines originally developed at Harvard. John Eichorn, et al, Standards for Patient Monitoring During Anesthesia at Harvard Medical School, 256 J Am Med Ass'n 1017 (1986); P. McGinn, Practice Standards Leading to Premium Reductions, Am Med News 1 (December 2, 1988).

3. "Defensive" medical care is provided less for the patient's benefit than to protect the physician from exposure to possible malpractice liability. Unnecessary tests and treatments that are provided only to satisfy an unreasonable standard of care that the physician imagines some future 
improve the ability of the legal system and liability insurers to determine when actionable medical negligence has occurred.

This article considers the usefulness of practice guidelines in the law of medical malpractice. It first takes a more or less conventional view of both practice guidelines and the tort system, explaining how guidelines will assist in setting legal standards of care that are both clearer and more rational than those that courts are currently using to identify professional negligence. The article then, however, suggests an alternative strategy for using practice guidelines. Instead of visualizing a definitive set of guidelines that would be used to set the general tort-law standard for all care, the article recommends encouraging the development of competing guidelines that might take different positions on specific issues. Such a strategy would be expressly designed to give health care providers, payers, and consumers new opportunities to choose a specific standard to govern their particular relationship. Thus, even though formulating better prescriptive standards of medical practice would materially improve the tort system as a program of quality-assurance regulation, the guidelines movement holds out an even more exciting prospect. If allowed to develop pluralistically, it could provide the means for finally "deregulating" the health care field-by greatly expanding consumers' ability to specify what they do and do not wish to purchase in the way of medical services. For the law of medical malpractice, the view of practice guidelines ultimately advanced in this article implies a long overdue shift from tort to contract-from a form of command-andcontrol regulation to consumer choice. ${ }^{4}$

\section{The Practice Guidelines Movement}

Practice guidelines have emerged rapidly in the last several years as the medical profession's main answer to revelations of significant shortcomings in prevailing medical practice. During the $1980 \mathrm{~s}$, health services research produced increasing evidence of inexplicably wide variations in physicians' diagnostic and treatment methods, ${ }^{5}$ of serious weaknesses in the scientific underpinnings of many customary practices, ${ }^{6}$ and of substantial overuse of

plaintiff's lawyer might assert is widely believed to be a major contributor to high medical costs. See generally Nathan Hershey, The Defensive Practice of Medicine: Myth or Reality?, 50 Milbank Memorial Fund Q69 (1972); Project, The Medical Malpractice Threat: A Study of Defensive Medicine, 1971 Duke LJ 939-48. There is some basis for expecting that practice guidelines will give physicians some of the confidence needed to do only what is medically indicated.

4. For a series of articles discussing other ways of using private contracts to reform the rules governing medical malpractice, see Symposium, Medical Malpractice: Can the Private Sector Find Relief?, 49 L \& Contemp Probs 1, 143-320 (Spring 1986). See also note 39.

5. See, for example, Mark Chassin, et al, Variations in the Use of Medical and Surgical Services by the Medicare Population, 314 New Eng J Med 285, 286-87 (1986); John Wennberg, Dealing with Medical Practice Variations: A Proposal for Action, Health Affairs 6, 7 (Summer 1984); John Wennberg \& Alan Gittelsohn, Small Area Variations in Health Care Delivery, 182 Sci 1102 (1973).

6. See, for example, David Eddy \& John Billings, The Quality of Medical Evidence: Implications for Quality of Care, Health Affairs 19, 20 (Spring 1988) ("for at least some important practices, the existing evidence is of such poor quality that it is virtually impossible to determine even what effect 
many medical and surgical procedures. ${ }^{7}$ These revelations undermined one of the crucial premises on which the health care industry has long operatednamely, the assumption that, by and large, individual physicians are guided by medical science and the norms and standards of their profession to pursue appropriate courses of diagnosis and treatment. In addition to raising general concerns about the quality of medical care, the researchers' look inside the black box of medical practice gave those who are responsible for paying for health services in both the public and private sectors good reason to question whether there are any reliable hands at all on the controls governing the direction and rate of health care spending. ${ }^{8}$

With payers, politicians, and other representatives of the general public questioning its collective performance as well as the judgment and integrity of individual physicians, the medical profession launched major new initiatives to develop and disseminate practice guidelines. The Clinical Efficacy Assessment Project of the American College of Physicians was one of the first and most extensive efforts. ${ }^{9}$ Other medical specialty societies have also taken concrete steps, increasingly going beyond mere sampling of professional opinion and instead seeking to place medical practice on a firmer scientific base. 10 The American Medical Association ("AMA") has actively encouraged professional groups to promulgate what it prefers to call "practice parameters" and has laid down criteria and procedures for their development. ${ }^{11}$ Although these initiatives represent a sincere effort by the medical profession to improve its stewardship of the health care system, they may also be interpreted as an attempt to preserve professional dominance

the practice has on patients, much less whether that effect is preferable to the outcomes that would have occurred with other options"); David Eddy, Clinical Policies and the Quality of Clinical Practice, 307 New Eng J Med 343 (1982) ("[T]here is reason to believe that there are flaws in the process by which the profession generates clinical policies.").

7. See, for example, Robert Brook, et al, Predicting the Appropriate Use of Carotid Endarterectomy, Upper Gastrointestinal Endoscopy, and Coronary Angiography, 323 New Eng J Med 1173 (1990) ("[W]e concluded that 17 percent of coronary angiographies, 17 percent of endoscopies, and 32 percent of endarterectomies represented inappropriate overuse [using a liberal standard]. In addition, we considered that the use of the procedure was equivocal (that is, the health benefit and risk were approximately equal) in 9,11 , and 32 percent of the procedures, respectively.")

8. Economist Kenneth Arrow marveled in the early 1960 s that a variety of nonmarket mechanisms had emerged-apparently through the working of an invisible hand unappreciated by Adam Smith-to substitute for unworkable market forces in the health care sector. Kenneth Arrow, Uncerlainty and the Welfare Economics of Medical Care, $53 \mathrm{Am}$ Econ Rev 941 (1963). That sanguine view was later challenged by sociologist Paul Starr, who observed that the system was in fact manipulated by the medical profession. Paul Starr, The Social Transformation of American Medicine 226-27 (Basic Books, 1982). The practice guidelines movement offers yet another opportunity to consider which invisible hand-the profession's or the market's-is more likely to steer systematically toward efficiency in the allocation of society's resources and therefore should direct decision making on medical care. Compare with note 22.

9. See Institute of Medicine, Assessing Medical Technologies 275-85 (Nat'l Acad Press, 1985).

10. See Council on Health Care Technology, Institute of Medicine, Medical Technology Assessment Directory: A Pilot Reference to Organizations, Assessments and Information Resources (Nat'l Acad Press, 1988); Am Med Ass'n, Office of Quality Assurance, Listing of Practice Parameters, Guidelines, and Technology Assessments (November 1989) (53-page list).

11. Am Med Ass'n, Office of Quality Assurance, Attributes to Guide the Development of Practice Parameters (1990). 
over medical decision making and to head off further interference by payers and other intermediaries increasingly distrustful of professionalism as a control mechanism. Indeed, physicians appear to hope that by voluntarily supplying better professional standards, they will be able to prevent the collapse of their preferred paradigm of medical care, under which they are held accountable only under norms and standards that they themselves develop. ${ }^{12}$

The movement to develop authoritative practice guidelines received important new impetus in the budget reconciliation legislation adopted in the Fall of 1989. ${ }^{13}$ In that law, Congress created a new Agency for Health Care Policy and Research ("AHCPR") in the Public Health Service ("PHS") and assigned it specific responsibilities for conducting and commissioning research focusing on the actual outcomes and effectiveness of medical treatments. The legislation also created a separate office within the AHCPR, called the Forum for Quality and Effectiveness in Health Care ("Forum"), and expressly charged it with appointing panels of physician experts and consumer representatives to preside over the development of practice guidelines based to the greatest extent possible on the findings of outcomes and effectiveness research. Although these panels may develop guidelines themselves, they are also free to adopt guidelines developed by contractors appointed by the Forum and by independent organizations working on their own. At this writing, the Forum's efforts are just getting under way. ${ }^{14}$ Given the magnitude of the task of laying new scientific foundations for and ultimately rationalizing all medical practice, it seems unreasonable to expect the federal guidelines program to deliver fully on its considerable promise much before the next century. Nevertheless, there is reason to anticipate that substantial improvements in medical practice will result from the efforts being made.

It is notable that Congress carefully provided that panels of private citizens, rather than the Forum as such, would formally adopt the practice guidelines to be produced. Although the panels are to follow the Forum's criteria and standards in their work, ${ }^{15}$ Congress clearly wished the guidelines produced to have only advisory, not official, status. On the other hand, Congress took special steps to give the panels a high degree of political legitimacy by providing that a variety of interests would be represented in their membership. ${ }^{16}$ One interpretation of these provisions is that Congress

12. See generally Clark Havighurst, The Professional Paradigm of Medical Care: Obstacle to Decentralization, 30 Jurimetrics J 415 (1990).

13. Omnibus Budget Reconciliation Act of 1989, Pub L No 101-239, $\$ 6103$, to be codified in 42 USC $\S 299$, adding Title IX to the Public Health Service Act and section 1142 to the Social Security Act. Hereinafter, this legislation is referred to by citing the affected acts

14. See Program Note, Clinical Guideline Development (AHCPR, 1990) (describing state of program); Institute of Medicine, Clinical Practice Guidelines (cited in note 1) (advice to AHCPR on implementation of guidelines program).

15. Public Health Service Act $\S 914(\mathrm{~b})$.

16. Id $\$ \S 913(\mathrm{a})(2)$, (c), 914(b)(3)(A); HR No 101-247, 101 st Cong, 1st Sess 378 (1989). See also Havighurst, 34 St Louis U L J at 786-88 (cited in note 1). Recent legislation in Maine, reflecting 
wanted the guidelines emanating from the program to be politically as well as technically authoritative, facilitating their use for quality-assurance and costcontainment purposes in public programs such as Medicare and Medicaid. In this same political spirit, Congress located the guidelines project in the PHS rather than in the Health Care Financing Administration, hoping thus to allay concerns that guidelines would be driven primarily by budgetary rather than medical considerations. Although Forum-generated guidelines will not be incorporated automatically in the Medicare program, the legislation lays political groundwork that will ease their adoption at a later date.

Some tension exists between the purely professional model within which organized medicine is pursuing the development of practice guidelines and the political model that is implicit in the federal program. ${ }^{17}$ Although conflict between the two ways of generating guidelines remained latent as the consensus on the need for guidelines was building, some controversy is likely as the Forum selects its panels and contractors and as guidelines are developed under different auspices and put into use. Guidelines produced under the respective models will differ most with respect to their prescriptiveness. Profession-sponsored guidelines will focus primarily on establishing floors (below which care may be deemed inadequate or incompetent) and ceilings (above which care may be deemed unnecessary and unreimbursable). The range between these boundaries-or parameters, as the AMA calls them-will tend to be fairly wide except where the scientific evidence supporting a particular course is very clear. Not only would a professional organization be reluctant to rule out any practice supported by an appreciable number of its members, but one of its prime goals would be to protect the clinical freedom of practitioners. Although professionally promulgated boundaries of acceptable practice would be of some help in detecting overuse, underservice, and professional negligence, such guidelines would usually be more permissive than guidelines developed with input from consumer interests concerned only about raising quality and containing costs.

The potential differences between the two models of practice guidelines may be less important, however, than the common ground they share. Both models visualize guidelines in the same essentially regulatory way-as the sole authoritative source to which physicians, public financing programs, private insurers and other payers, physician peer reviewers, public disciplinary bodies, courts, and indeed the entire society should look for benchmarks establishing the appropriateness or inappropriateness of medical treatments. Therefore, any tension that exists between the two models concerns, not

the same political impulse, provides for guidelines developed by panels with similarly diverse representation. 1990 Maine Pub Laws ch 931 (April 24, 1990); George Smith, Maine's Liability Demonstration Project-Relating Liability to Practice Parameters, State Health Legis Rep 1, 2-3 (Fall 1990).

17. The professional and political models of practice guidelines are described, documented, and compared in Havighurst, 34 St Louis U L J at 784-92 (cited in note 1). For a perspective reflecting the professional paradigm of medical care, see Leahy, 77 Cal L. Rev 1483 (cited in note 1) (recommending that guidelines developed by dominant specialty societies be given judicial notice and conclusive effect in malpractice cases). 
whether medical care requires highly centralized, prescriptive regulation, but only the degree of flexibility that is appropriate in prescribing for a highly diverse health care system. ${ }^{18}$ The issues are thus no different than those surrounding any program of command-and-control regulation: Who should set the regulatory standards, and how liberal or restrictive should they be? Moreover, one should not confuse the adoption of more permissive standards, such as the medical profession prefers, with responsible deregulation. Unless a market exists in which people can effectively express alternative preferences concerning how their funds are spent, the effect of a laissez-faire regulatory policy may be only to reduce physicians' accountability. Precisely because a consumer-driven market remains elusive in health care, the coming battle to capture the machinery for making practice guidelines may be little more than another skirmish in the long war between the medical profession and political institutions for control of the health care system's regulatory apparatus. Neither side contending in this war questions the assumption that practice guidelines are to serve as a kind of prescriptive regulation governing medical practice.

As a result of this consensus on the need for centralized decision making in medical care, practice guidelines are very likely to serve essentially regulatory functions in the U.S. health care system. Even though they are promulgated by groups of private citizens and not by government as such, guidelines that are produced by a dominant professional organization or that enjoy political legitimacy under the federal guidelines program would be not only the logical, but practically the mandatory, point of reference for resolving payment issues. ${ }^{19}$ Likewise, authoritative guidelines, once available,

18. Even politically developed guidelines would have to make allowances for the wide differences in practice settings, in schools of medical thought, and in patients' basic health, prospects, preferences, and economic circumstances. There are also powerful pressures to leave room for the "art" as well as the science of medicine. Although professional interests would probably be more tolerant at both ends of the scale than consumer-oriented decision makers would be, the difference would be only one of degree, not fundamental conception. See note 20.

19. Private health insurers are eager for practice guidelines developed "with the participation of the physician community .. . by nongovernmental agencies." Health Ins Ass'n Am, The Health Insurance Industry Strategy for Containing Health Care Costs xiii-xiv (1990) (report of board of directors). That they envision only a single authoritative point of reference on questions of medical practice is clear from their desire for "a mechanism . . . to grant certification of medical efficacy and costeffectiveness to newly developed procedures, technologies and equipment before they become part of common medical practice." Id at xiv. Likewise, courts, both reflecting and reinforcing the preferences of government and private insurers for centralizing hard choices concerning medical care, could be expected to give authoritative guidelines great weight-approaching regulatory effect-in construing statutory or contractual payment obligations, which are usually phrased in terms of "appropriateness" or "medical necessity." Although guidelines will often establish a range of acceptable practice rather than an actual "cookbook" to be slavishly followed, payers seeking to economize would probably find it legally difficult to refuse payment for any services that fall within the range of acceptability. (On the legalities of utilization management, see note 58.) Certainly the medical profession believes that physician discretion alone should govern within that range, and courts have frequently defined payers' obligations to encompass all treatments that are medically recognized. See, for example, Sarchett $v$ Blue Shield of California, 43 Cal 3d 1, 233 Cal Rptr 76, 729 P2d 267 (1987) (upholding policy provision making peer-review committee of medical society the final arbiter of plan coverage); Annotation, What Services, Equipment, or Supplies Are "Medically Necessary" for Purposes of Coverage under Medical Insurance, 75 Admin L Rep 4th 763 (1990). 
would almost certainly serve as virtually the exclusive standard used by licensing authorities, peer reviewers, and malpractice courts in evaluating the performance of individual physicians. The analysis in the next section of this article, considering how practice guidelines might improve the tort system's ability to identify medical negligence, will generally assume that practice guidelines are indeed intended to serve an essentially regulatory purpose. Because this regulatory conception of guidelines dovetails well not only with the professional and political paradigms of medical decision making but also with the prescriptive tendencies of malpractice law itself, it is likely to prevail over any alternative conception.

The regulatory scenario is not, however, the only possible one. Despite all the centralizing tendencies inherent in the professional, political, and legal paradigms of medical care, pluralism may still survive. One possibility is that the various parties interested in the substance of practice guidelines in particular areas of practice will not be able to agree upon a single set of specifications, ${ }^{20}$ even of the unrestrictive boundary variety. ${ }^{21}$ Another possibility is that the federal guidelines program will take affirmative steps to foster pluralism, not as an end in itself, but to supply decision makers with verified facts and a variety of analyses that could facilitate the design and administration of innovative, cost-effective health plans and the exercise of consumer choice. If in fact practice guidelines develop pluralistically, a very different scenario might evolve. Indeed, the health care industry might rather quickly be weaned from its exclusive dependence on professional norms and standards. Such deregulation of medical care could occur if the guidelines movement gave payers, physicians, and consumers clear-cut opportunities to choose alternative standards to govern their relationship. ${ }^{22}$ Although the

20. The large number of guideline-making efforts suggests that pluralism may indeed prevail Nevertheless, the federal guidelines program and professional efforts to set definitive standards could easily stifle it. The Council of Medical Specialty Societies ("CMSS") recently held a national conference to discuss means of resolving inconsistencies between guidelines of different professional groups, suggesting that, even though consensus may often be hard to achieve, the professional interests who are leading the way in guideline development are at least as convinced as government officials of the desirability of definitive standards. Report of Proceedings, CMSS Conference on "Resolving Conflict in the Design and Implementation of Practice Policies," Chicago, Ill, March 4-5, 1990 (copy on file with author). See Havighurst, 34 St Louis U L J at 790, 801 (cited in note 1) (suggesting antitrust problems in agreements eliminating competition between guidelines covering the same topic, as contemplated by the CMSS conferees); see also Clark Havighurst, The Antitrust Challenge to the Paradigm of Medical Law 12-17 (1990 Michael M. Davis Lecture, Center for Health Administration Studies, University of Chicago).

21. True pluralism requires more than boundary guidelines (or parameters) that leave physicians room to exercise clinical judgment. "Flexibility allowed in a single set of practice guidelines is not the same thing ... as the pluralism that would result from the ability of users to choose among a number of competing guidelines each expressing a slightly different (but internally consistent) valuation of medical care and degree of risk aversion." Havighurst, 34 St Louis U L J at 800 (cited in note 1 ).

22. Note how the discussion here connects the practice guidelines movement with the larger issues in health policy in the last two decades, which have been described as follows:

Until [the late 1970s], little in the health policy debate challenged the prevalent assumption that the health care system must operate under prescriptive standards of acceptable care and appropriate spending. Instead, the issue debated was whether the medical profession alone should define these performance limits or whether government should exert an 
next section of this article assumes, for the most part, that the nation will continue to follow its conventional regulatory impulses with respect to medical care, that assumption will be relaxed in the final section, revealing more fully the alternative path that the practice guidelines movement could open up.

\section{Practice Guidelines as an Aid in Regulating Medical Care Through the Tort System}

With all the attention being paid to the law of medical malpractice, it is surprising that it is so rarely characterized or analyzed as a system of command-and-control regulation. Although tort law serves an ostensibly remedial purpose and thus operates only after an injury has occurred, its prospective, regulatory character is salient in its application of prescriptive standards to determine provider fault as a prerequisite of liability. In addition, the law's sanctions effectively compel observance of its requirements. Even though malpractice insurance relieves a physician of nearly all the direct financial cost of negligently caused injuries, a malpractice suit remains highly stressful and distracting, and exposes the physician defendant to harmful publicity and other burdens. ${ }^{23}$ To avoid entanglement with the legal system, most physicians strive to conform their behavior to the law's expectations, as they perceive them. Because the prospect of being sued for substandard performance is intended to, and apparently does, influence physician performance, malpractice law is similar in its impact to prescriptive regulation. ${ }^{24}$

influence. When the advocates of competition entered the discussion, however, they
rejected both professional self-regulation and government command-and-control methods
as mechanisms for resolving medical-economic issues. Their scenario opened the
possibility that consumers would have a chance to decide for themselves in the marketplace
what standards of medical practice best suited their preferences and pocketbooks. In
essence, the market reformers contemplated that decision-making responsibility could be
shifted to the numerous actors on the demand side of the market and that consumers could
safely be encouraged to do business with health plans and providers whose practices
departed from accepted norms. In particular, procompetition strategists anticipated that
cost considerations would be given greater weight in medical decision making if those
paying the bills were given a wider range of choice. Clark Havighurst, Decentralizing Decision Making: Private Contract versus Professional Norms, in Jack Meyer, ed, Market Reforms in Health Care 22, 23-28 (Am Enterprise Inst Pub Pol'y Res, 1983) ("Decentralizing Decision Making"). See also Havighurst, 30 Jurimetrics J 415 (cited in note 12) (discussing the continuing influence of the "professional paradigm" of medical decision making); Havighurst, The Changing Locus of Decision Making in the Health Care Sector, $11 \mathrm{~J}$ Health Pol, Pol'y \& L 697 (1986) (discussing progress in decentralizing decisions).

23. Although malpractice insurance is usually not experience-rated, physicians with multiple claims may anticipate difficulty in retaining coverage as well as adverse consequences in their dealings with hospitals, other physicians, and regulatory authorities. An additional sanction was added by the Health Care Quality Improvement Act of 1986, which requires that all payments made in settlement of malpractice claims be reported to a federally maintained data bank. 42 USC $\$ 11131$ (1988); 45 CFR $\$ 60.7$ (1990). Such black marks will presumably affect physicians' future prospects adversely.

24. For an inconclusive discussion of the question of the impact of liability risks on physician behavior, see Harvard Medical Practice Study, Patients, Doctors, and Lawyers ch 9 (cited in note 2). 
Malpractice law is usually said to have two coequal objectives: compensating injured persons and deterring medical negligence. But because very high administrative costs are incurred in deciding whether compensation is warranted in particular cases, the law's retention of fault as a criterion for the imposition of sanctions is difficult to justify unless the legal standard of care induces physicians generally to practice in ways that are socially appropriate. ${ }^{25}$ Although serious doubts about malpractice law's overall utility are currently justified, the guidelines movement may provide just the improvements that are needed to make the tort system defensible as a sensitive mechanism of quality-assurance regulation. In any event, even though most analysts treat malpractice law on its own terms as a matter of individual rights, it is more helpful for policy purposes to analyze it as essentially a regulatory program.

Paradoxically, practice guidelines could substantially improve the quality of regulation imposed by malpractice law on medical practice without being a critical factor in very many malpractice cases. Indeed, guidelines will be of forensic use only in those cases in which the issue is whether the doctor chose the wrong course of diagnosis or treatment or should have gone farther (that is, spent more) in attempting to understand or correct the situation. Most malpractice claims, however, involve allegations of clear errors of omission or commission, turn primarily on factual questions, or raise only causation or damages issues. ${ }^{26}$ Nevertheless, even though practice guidelines may only occasionally resolve a dispute crucial in the litigation of an actual malpractice claim, they can still contribute greatly to addressing what appears to be the larger policy problem that malpractice law presents-namely, its inducement to physicians to use resources inefficiently.

\section{A. Improving the Standards Used in Administering Tort Law}

Viewed specifically as command-and-control regulation, current malpractice law has some fundamental shortcomings that practice guidelines may be able to remedy. The legal system could benefit both from guidelines'

\footnotetext{
"Physicians of a given specialty with a higher perceived risk of being sued were more likely to order more tests and procedures than their colleagues with a lower perceived risk." Id at 29-30. The phenomenon of defensive medicine (see note 3), while difficult to measure, suggests that the law does indeed influence physician conduct, sometimes in inappropriate ways.

25. On the cost of administering the fault-based malpractice system, see Patricia Danzon, Medical Malpractice: Theory, Evidence, and Public Policy 186-87 (Harvard U Press, 1985) (reporting estimates of share of the premium dollar ultimately received by injured patients as low as $18 \%$ and Danzon's own estimate of roughly $33 \%$ ). If tort law does not in fact perform its regulatory function reasonably well, the fault criterion for compensation should either be dispensed with altogether or be redefined in some way so that it does indeed channel medical practice in appropriate directions. See id at 225 26 ("rough calculation suggests that if the number of negligent injuries is, generously, 20 percent lower than it otherwise would be because of the incentives for care created by the malpractice system, the system is worth retaining, despite its costs"). On no-fault approaches, favored both to reduce transaction costs and to improve incentives to improve outcomes of treatment, see Laurence Tancredi, Designing a No-Fault Alternative, 49 L \& Contemp Probs 277 (Spring 1986).

26. See generally Thomas Metzloff, Resolving Malpractice Disputes: Imaging the Jury's Shadow, 54 L \& Contemp Probs 68-76 (Winter 1991).
} 
greater clarity in comparison to the vagueness of current legal standards and from their probable substantive superiority. The discussion here concludes that introducing practice guidelines could materially improve the tort system as a regulatory program. ${ }^{27}$

1. Clarifying the Law's Requirements. As malpractice law is currently administered, its requirements are extraordinarily vague and unpredictable. Indeed, what the law requires of physicians in the many gray areas of medical practice is seldom specified concretely. Instead, the law's standard is often only implicit in the verdict of a lay jury, which is rendered after hearing conflicting testimony from medical experts. Although expert witnesses are supposed in theory to rely upon objective professional standards, subjective judgment inevitably plays a large role. Moreover, experts are not impartial. Instead, they are selected by the parties with a view to the positions they will take and their skill in persuading juries. Given the considerable vagueness of the standards it imposes so rigorously on physicians, the tort system would probably not survive scrutiny under constitutional norms of due process if it operated as a public regulatory program de jure as well as de facto. Because the law sends such uncertain signals, it is probable that physicians tend to give it a very svide berth, tailoring their clinical practices on the assumption that the legal system will have unreasonable expectations if and when it has an occasion to review their performance.

It remains to be seen whether and how often practice guidelines will be clear and specific enough to establish a standard of care usable by juries in malpractice cases and by physicians in making defensible clinical decisions. There is little doubt, however, that they will eventually be more explicit and more helpful than the vague standards that the tort system currently enforces. Guidelines should therefore lower litigation costs by simplifying some trials and by making some trial outcomes more predictable, facilitating settlements. Although guidelines could facilitate the bringing of more malpractice suits by revealing negligence that would otherwise go undetected, they should also reduce the need for some malpractice litigation by enabling physicians to practice in ways that create fewer legal risks. Most important, clarification of what the law expects should also reduce the cost of defensive medicine by improving physicians' ability to estimate the limits of their legal duties. There is certainly every reason to expect that practice guidelines can improve the tort system's regulatory performance-if that is how society chooses to use them.

2. Shortcomings of the Customary-Practice Standard. The substantive standards that the tort system currently employs in regulating medical practice are drawn, ostensibly at least, from customary medical practice, which is

27. For recent evaluations reaching a similar conclusion, see Mark Hall. The Defensize Effect of Medical Practice Policies in Malpractice Litigation, 54 L \& Contemp Probs 119 (Spring 1991); Troyen Brennan, Practice Guidelines and Malpractice Litigation: Collision or Cohesion?, $16 \mathrm{~J}$ Health Pol, Pol'y \& L 67 (1991). 
ordinarily established through the testimony of expert witnesses. Originally, the standard was the custom prevailing in the particular locality in which the plaintiff's treatment was provided. But plaintiffs often found it hard to get community physicians to testify against their colleagues. For that reason and also to prevent local practice from lagging behind good practice elsewhere, the courts came to allow witnesses from "similar communities" to testify concerning the appropriate standard of care. ${ }^{28}$ Eventually they decided that specialists, at least, should be held to national rather than purely local standards. ${ }^{29}$

The law's reliance on medical custom, local or national, as its source of substantive standards is difficult to justify. First, it assumes that physicians, left to their own devices, generally practice in ways that are socially correct. Yet, as we know from health services research, medical practice, instead of reliably gravitating toward uniform methods reflecting deep scientific understanding and careful weighing of all options, varies inexplicably not only between geographic areas but even within the same community. This heterogeneity of medical practice, in addition to being one of the factors inducing interest in practice guidelines, gives expert witnesses in malpractice cases great freedom in opining on the standard of care. To the extent, then, that the questionable performance of juries in assigning fault in malpractice cases is attributable to the law's reliance on a source of standards that is incapable of producing anything worthy of the name, practice guidelines will improve the situation. Even though guidelines will never have the infallibility or the specificity needed to resolve every case conclusively, they should settle many disputes, clarify the issues in other cases, and generally reduce both uncertainty and the discretion of lay juries.

Even when medical custom does yield clear standards for regulating medical practice, the substantive validity of those standards may be open to serious question because medical practice may be either poorly grounded in science $^{30}$ or economically inefficient. In tort actions in nonprofessional fields, courts generally treat the custom of a trade regarding safety measures as relevant (though not conclusive) evidence of appropriate care. They do so partly because such evidence suggests what precautions have generally been found to be worth their cost. ${ }^{31}$ With respect to medical care, however, custom is a poor guide to what is economically justified. Customary medical practices have evolved in the United States under systems of paying for medical care that create economic incentives for both physicians and patients to overutilize services, spending more on marginal benefits than they are in any sense

28. For example, Shilkrel $v$ Annapolis Emergency Hosp. Ass in, $276 \mathrm{Md} 187.349$ A2d 245 (1975).

29. For example, Hall $v$ Hilbun, 466 So 2d 856 (Miss 1985).

30. See notes 6, 7. For a case demonstrating the substantive superiority of practice guidelines over standards derived through expert testimony, see Leahy, $77 \mathrm{Cal} \mathrm{L} \mathrm{Rev} \mathrm{at} 1499-1502$ (cited in note 1) (discussing Ornoff $v$ Kuhn $\mathcal{E}^{2}$ Kogan Chartered, 549 A2d 728 (DC 1988)).

31. See William Landes \& Richard Posner, The Economic Structure of Tort Law 131-39 (Harvard U Press, 1987): Randall Bovbjerg, The Medical Malpractice Standard of Care: HMOs and Customary Practice, 1975 Duke L J 1375, $1384-1407$. 
worth. ${ }^{32}$ For the tort system to enforce adherence to practice norms arising spontaneously under an incentive system fraught with moral hazard is to convert an inefficiency that may be acceptable as a necessary cost of financial protection into a mandatory burden on society. ${ }^{33} \mathrm{~A}$ proper definition of defensive medicine would include not only wasteful efforts by physicians to make themselves look good before a jury but also conscientious efforts to follow practices of the professional community that have become customary despite their inappropriateness in terms of benefit/cost ratios.

Although cost considerations have intruded more and more into medical decision making in recent years, it is doubtful that the system has yet learned how to balance benefits against costs in any coherent way. Indeed, malpractice fears are regularly cited as a reason why physicians cannot be more cooperative in cost-containment efforts. In theory, of course, the legal system should be able to detect shifts toward more economical practices and to excuse physicians who follow such shifts. Even in theory, however, tort law allows departures from dominant practice only after the new practices have come to be followed by a so-called "respectable minority" of physicians. ${ }^{34}$ Thus, in theory as well as practice, the legal system continues to expose innovators to serious liability risks. In addition, juries often remain free as a practical matter to find liability solely on the basis that more could have been done for the individual patient. The customary-practice rule would seem distinctly ill-suited for an industry that is heavily impacted by insuranceinduced moral hazard and gravely in need of fundamental change in practice styles. Efficient economizing should not be deterred simply because it may occasionally be accompanied (often only fortuitously) by an unfortunate medical result.

Practice guidelines can be expected to give somewhat more weight to cost considerations than such considerations have received in the evolution of customary medical practice. ${ }^{35}$ But even guidelines that are developed with input from cost-conscious consumer representatives are unlikely to resolve

32. See Bovbjerg, 1975 Duke L J at $1392-97$ (cited in note 31).

33. Moral hazard arises whenever one person (for example, a doctor or a patient) is in a position to spend or risk resources belonging to another (for example, a health insurer). See Paul Joskow, Controlling Hospital Cosis: The Role of Government Regulation 22-24 (MIT Press, 1981). As Joskow explains, inefficiency attributable to moral hazard may be an acceptable cost of financial protection against unpredictable medical needs as long as payers have taken all cost-effective steps to minimize that cost. Ironically, however, once an inefficient standard of care has become entrenched through the influence of moral hazard, payers may find themselves legally bound, under professional norms, to continue paying for care that would not be ordered if costs were faced. See note 19

34. See, for example, Chumbler v McClure, 505 F2d 489, 492 (6th Cir 1974): "The test for malpractice and for community standards is not to be determined solely by a plebiscite. Where two or more schools of thought exist among competent members of the medical profession concerning proper medical treatment for a given ailment, each of which is supported by responsible medical authority, it is not malpractice to be among the minority in a given city." For a discussion of the "reputable minority" principle as a defense for $\mathrm{HMO}$-style medical care, see Bovbjerg, 1975 Duke $\mathrm{L}$ $J$ at $1408-14$ (cited in note 31 ).

35. Even professional groups, recognizing their need to retain credibility with public and private payers, will not ignore cost considerations entirely. See, for example, Leahy, 77 Cal L Rev at 1515 19 (cited in note 1 ). 
difficult trade-offs for the entire society. The widespread belief that health care is an entitlement not to be economically rationed, combined with physicians' desire for clinical freedom, makes it probable that guideline makers will approve any practice that enjoys the support of respectable practitioners if it has not conclusively been shown to yield no medical benefit not obtainable at lower cost by other means. Instead of addressing difficult trade-offs between marginal quality and marginal cost, guideline developers will focus most of their attention on medical issues, pretending that economic trade-offs either do not exist or are someone else's responsibility. Even though efforts to specify scientifically grounded standards of care will certainly improve the performance of the tort system, such technocratic regulation of medical practice through the mechanisms of tort law would still lack the tools needed to achieve efficiency in medical care.

3. Returning Standard Setting to Professional Control. In view of physicians' antipathy to the law of medical malpractice, it may be surprising to learn that tort-law doctrine goes quite far toward embracing the medical profession's own view of how the medical care enterprise should be regulated. Essentially, the law shares the profession's view that there exists one set of socially appropriate standards of medical care (which in many circumstances may consist of a range of acceptable practices) that should apply in all practice circumstances and that only the medical profession is competent to supply. ${ }^{36}$ The law's use of customary practice as its benchmark for evaluating the performance of individual professionals was originally entirely congruent with the medical profession's belief that physicians should be policed only by standards of their own making. ${ }^{37}$ Likewise, the requirement that negligence must ordinarily be established by the testimony of qualified medical experts was also designed to subject physicians only to rules having the profession's backing. It is striking that the main reasons why physicians now feel oppressed by malpractice law are (1) that the professional standards on which the law relied turned out to be so imprecise and variable as to leave juries wide discretion in imposing liability and (2) that the medical profession gradually lost its previous ability to influence the testimony of physician witnesses. ${ }^{38}$ It is simply ironic that the legal regime about which the medical profession so loudly complains continues to embody the profession's own

36. See generally Havighurst, 30 Jurimetrics J 415 (cited in note 12).

37. See generally Allan McCoid, The Care Required of Medical Practitioners, 12 Vand L Rev 549 (1959). Even Helling $\because$ Carey, 83 Wash 2d 514, 519 P2d 981 (1974), the most famous exception to the policy of allowing physicians to set their own standards. effectively proved the rule. In that case, the court applied its own intuition to find negligent a practice (not testing persons under forty routinely for glaucoma) that was clearly sanctioned by professional custom. Other courts have not assumed similar power to second-guess professional judgment.

38. Although efforts to intimidate plaintiffs' witnesses continue, for example, Mever " VcDonnell, $40 \mathrm{Md}$ App 524, 392 A2d 1129 (1978), professional experts are rather widely available today, though subject to impeachment for possible bias. See Annotation. Propriety of Cross-Examining Expert Witmess Regarding His Status as "Professional IIimess." 39 ALR 4th 742 (1985) 
philosophy of self-regulation and to adhere, in theory at least, to standards that the profession itself supposedly sets.

The medical profession's recent moves to establish practice guidelines are perhaps best understood as an effort by the profession to reclaim its former authority over the setting of standards to which physicians are generally held. Not only is the profession's claim to such authority not at all at odds with the legal system's conception of how and by whom the medical profession should be regulated, but there is continuing acceptance by nearly everyone concerned-the medical profession and opponents of tort reform alike-of the tort system's regulatory character. Likewise, the popularity of practice guidelines in both medical and legal circles lies largely in their perceived potential for improving the quality of self-regulation to which the legal system subjects physicians. Although the possibility of actual deregulation-giving consumers freedom to write their own standards for medical care and their own rules for enforcing those standards-has never been very seriously entertained in the debate over tort reform, ${ }^{39}$ discussion in the last section of this article will quarrel with the regulatory premise of this conventional view of practice guidelines.

\section{B. The Relevance of Practice Guidelines in Malpractice Cases}

Although practice guidelines will probably not be of central significance in resolving many actual malpractice claims, there will be some cases in which they are relevant. It is therefore necessary to consider precisely how their evidentiary value will be established in litigation. Guidelines could, of course, be made binding on physicians by statute or regulation, in which case they would be applied automatically by malpractice courts as the standard of care to which physicians must conform; departures from the guidelines would presurnably constitute negligence per se. But short of such explicit regulation, a question remains as to how a practice guideline will become recognized by courts and juries as the standard to which a physician is held in a malpractice case..$^{40}$ Almost certainly some kind of expert testimony will still be required whenever a plaintiff seeks to introduce a guideline as evidence of the standard that the defendant breached or a defendant physician relies on a guideline to justify his conduct. In addition, although practice guidelines introduced into evidence may be given great weight by finders of fact, they are unlikely to be treated as conclusive evidence of the standard either in law or in practice. Thus, violations of the guidelines will probably not be deemed

39. Although the idea of relying on private contract to reform the rules governing medical malpractice has received academic attention, see note 4, it has not been acted upon anywhere. Indeed, it has met great resistance by the legal culture, which acknowledges only the risks and none of the cost-saving benefits of contracts that diminish the role of courts and lawyers. See, for example, Maxwell Mehlman. Fiduciary Contracting: Limitations on Bargaining Between Patients and Health Care Providers, 51 U Pitt L Rev 365 (1990).

40. See generally Am Med Ass'n, Legal Implications of Practice Parameters at 11-22 (cited in note 1); Brennan, $16 \mathrm{~J}$ Health Pol, Pol'y \& L at 69-78 (cited in note 27); Kinney \& Wilder, 22 UC Davis L Rev at 442-50 (cited in note 1 ). 
negligence per se, and a demonstration of compliance will not conclusively establish due care. But even though a practice guideline is not selfauthenticating (as a true regulation would be), its practical effect would still be regulatory if it was easily introduced in evidence and juries usually gave it conclusive weight.

1. Guidelines as Evidence of Customary Practice. If the courts of a particular jurisdiction adhere rigorously to the traditional customary-practice rule, a practice guideline would not be admissible in evidence to prove the standard of care in a medical malpractice case unless it helped to establish medical custom. Most guidelines, however, will not be developed simply by observing actual medical practice and will therefore rarely even purport to be probative of custom as such. ${ }^{41}$ On the other hand, practice guidelines that purport only to describe what practices are acceptable could be admitted as evidence of customary practice if an expert testifies that practitioners in fact followed the guidelines once they were in place. Thus, guidelines might have to be influential in fact before they could be introduced to establish the standard of care. Testimony that guidelines are evidence of good practice would not be enough-at least if the court gives literal effect to the customary-practice rule.

Even if a court was satisfied that a particular set of guidelines was probative on the issue of custom, the guidelines, once admitted, might not be conclusive. A plaintiff's or defendant's counterevidence to the effect that actual practice departed from some specific guideline norm would presumably also be admissible. Moreover, if the guidelines left significant room for alternative practices or allowed variation within a range-as professionally developed guidelines in particular will often do-a plaintiff might attempt to litigate which practices, within the permissible range, were customary in fact. For example, if availability of financing induced physicians generally to practice at the top end of the specified range, the guidelines might provide no certain defense for care that met only the minimum standard. Or specialists might be held to the higher standard as a matter of course. On the other hand, a physician who met only the minimum standard but could demonstrate that it enjoyed some acceptance might be exonerated under the rule recognizing custom among a "respectable minority." 42 The same exception-or the similar one acknowledging the legitimacy of a separate "school of thought" - might even be invoked in defense of conduct falling outside the guidelines altogether. For these reasons, it seems clear that, at least as long as courts follow the narrow logic of the customary-practice rule, guidelines will not eliminate as much uncertainty, or save as much in litigation expense, as they would if the guidelines were embodied in a statute or binding regulation. Although guidelines might often predetermine the outcome of a

41. Even if they did purport to describe actual practice, a guideline would still constitute only hearsay evidence and would therefore be inadmissible without an expert witness's confirmation that it accurately portrays what is customary. See Brennan, $16 \mathrm{~J}$ Health Pol, Pol'y \& L at 74-76 (cited in note 27).

42. See note 34 . 
case by adding credibility to the testimony of one party's expert witness, they would not entirely obviate the battle of experts.

Guidelines would also lack probative value under the customary-practice formula if more than one set of guidelines existed to govern a particular area of practice and were inconsistent with respect to the treatment in question. In that event, expert testimony might address which set of guidelines was more influential in determining custom in the profession. Thus, because the auspices under which guidelines were produced would probably affect the extent of their influence, guidelines produced by a dominant specialty society might have more probative weight than guidelines produced by other means. Note, however, that it would not be simply the prestige or representativeness of the promulgating organization as such that makes its guidelines admissible but the greater likelihood that such an organization does in fact set the standard of practice. This argument for admissibility might evade the rule against hearsay evidence because the guidelines would be offered, not as outof-court testimony as to what is customary, but as the actual standard to which doctors generally conform.

The admissibility of guidelines that differ in substance from the guidelines of a more prestigious and influential medical organization would present some interesting questions. Because such guidelines are analogous to a scientific treatise, their substance would probably be admissible only if there were expert testimony to the effect that they either were customary in fact, reflected the practice of a respectable minority of the profession, or represented a separate school of thought. It is also probable that the narrow logic of the customary-practice rule would not be rigorously adhered to in evidentiary matters. Testimony that a guideline represents good scientific authority might well make it relevant and its substance admissible even without proof that the guideline was customarily followed. The issue would be sharply drawn if, say, the guideline bearing on the chosen treatment appeared only after the treatment was rendered.

Even though guidelines produced by a dominant professional organization and approved under the federal guidelines program would not enjoy exactly the same status in malpractice cases as a statute or binding regulation, the distinction between guidelines and regulations may prove to be more apparent than real. Some courts, perceiving guidelines as professional standards that they are charged with implementing, may implicitly or explicitly drop their adherence to the customary-practice rule and the requirement of a definite nexus between guidelines and actual medical practice. Authoritative guidelines might thus become the object of judicial notice, obviating expert testimony that physicians actually follow them. ${ }^{43}$

43. Judicial notice could be granted, however, only under the assumption that society has delegated to certain groups the task of devising standards of medical care. Although the federal guidelines legislation appears to strengthen the legal support for such an assumption, the federal program may be administered on a different basis. See text accompanying notes 76-78. For a proposal not only to admit practice guidelines developed by dominant medical organizations under 
Whether or not courts go this far, they are certain to receive authoritative guidelines in evidence under some theory, and juries can be expected to accord them great weight, particularly where they are offered by a plaintiff to establish a physician's negligence. In this latter respect at least, the tort system is likely to treat advisory guidelines, to the extent applicable, as essentially binding legal requirements. Thus, the introduction of authoritative practice guidelines into the tort system could easily make it even more obviously a system of command-and-control regulation centralizing crucial decision making largely in professional hands.

\section{Guidelines Under Alternative Formulations of the Standard of Care. Despite} what courts usually say in articulating the legal standard of care, customary practice is probably not, in any meaningful sense, the true source of the standards that courts actually apply in medical malpractice cases. The increasing use of variable national (rather than particular community) standards, the wide range of partisan experts available to the parties, the admission of testimony that is not strictly probative of custom, and the unhelpfulness of the vague instructions usually given to juries all suggest that juries in malpractice cases have wider discretion in practiçe than they have in theory. In light of this reality, courts might be more honest and more helpful to physicians, insurers, lawyers, and triers of fact if they would redefine the general legal standard of care. Instead of pretending that the test for medical negligence is specific and objective, they might recognize explicitly the possible relevance of standards that emanate from sources other than customary practice. ${ }^{44}$

One proposal for redefining the legal standard of care in malpractice cases would employ the principle of "acceptable practice." 45 This approach would provide some shelter for methods or economizing omissions that deviate from custom but that cannot be declared unacceptable by general professional standards. There would be a danger, however, that courts would look only to dominant professional organizations, rather than to a wider range of professional sources, for determinations of what is and is not acceptable, thus reinstating professional self-regulation. On the other hand, an arguable advantage of this legal standard is that it would not allow a physician to hide behind a professional custom that was generally deemed deficient by wellinformed professional authorities. Thus, the acceptable-practice rule would permit courts to correct backwardness in customary practices without substituting standards of their own invention for those emanating from

\footnotetext{
judicial notice but also to make them, without further legal warrant, conclusive of the standard of care, see Leahy, 77 Cal L Rev at 1522-27 (cited in note 1).

44. Although courts are free to reformulate the standard of care on their own, legislation might be the easier and more appropriate way in which to modify the command-and-control features of malpractice law and to erase the fiction that professional norms and standards provide reliable benchmarks for judging physician performance.

45. See Joseph King, The Law of Medical Malpractice in a Nutshell 44 (West. 2d ed 1986); Joseph King, In Search of a Standard of Care for the Medical Profession: The "Accepted Practice" Formula, 28 Vand L $\operatorname{Rev} 1213$ (1975).
} 
professional sources-as the Washington Supreme Court openly did in Helling $v$. Carey ${ }^{46}$ and as juries left at sea with poor instructions may often do.

Another way in which physicians' duties might be redefined would be simply to ask the jury to decide whether what the physician did was reasonable and prudent under all the circumstances. ${ }^{47}$ If properly administered, such a test would invite juries to focus, not just on adherence to custom, but also on the overall quality of the doctor/patient relationship and on such mitigating circumstances as the limited availability of financing or physical resources, other demands simultaneously placed on the physician, and the uncertainties that the physician faced. Note that the question is not what a hypothetical reasonable and prudent doctor would have done. (A "reasonable-andprudent-doctor" test would simply impose the uniform professional standard all over again.) Instead, the issue would be the reasonableness and prudence of the physician's actions-that is, whether what was done fell outside the range of what society should reasonably expect, an issue on which professional standards and expert testimony would be relevant but not conciusive. The jury's role would be to pass a societal rather than a substituted professional judgment, under instructions stressing that more than technical issues are involved.

Because both of these alternative ways of defining physicians' obligations acknowledge that medical practice can vary for a variety of legitimate as well as illegitimate reasons, adoption of either of them might reduce the command-and-control element that is implicit in the customary-practice rule and in any modification of it that also presumes the existence of a single uniform standard governing all care. Unfortunately, however, the success of any such attempt to reduce the regulatory tendencies of tort law would depend upon the outcome of the effort to develop practice guidelines. If only a single set of practice parameters was provided to cover each area of medical practice, those guidelines, if current, would probably be deemed to determine conclusively the full range of what is professionally "acceptable"; likewise, such guidelines would go far toward establishing what was "reasonable and prudent," if that were the test. Thus, either redefinition of the legal test for professional negligence might actually make the profession's own guidelines more determinative of the standard of care than is the customary-practice rule itself. It would be regrettable if doctrinal change had the effect of reestablishing professional self-regulation through the tort system rather than encouraging juries to consider factors other than simply what the profession as a whole officially declares to be appropriate care.

Only if the guidelines movement evolves in a pluralistic way, yielding a variety of alternative guidelines each produced by responsible analysts, would either alternative formulation of the law's test for physician negligence represent a significant break with the regulatory past. Under either legal test,

46. 83 Wash $2 d 514,519$ P2d 981 (1974). See note 37.

47. See, for example, Hood v Phillips, 554 SW2d 160, 165 (Tex 1977) (adopting a version of this test). 
any guidelines whose general credibility was established by expert testimony would presumably be admissible in a malpractice case as direct evidence for a jury to consider in evaluating the defendant physician's conduct. Such guidelines would be better indicators of the full range of socially acceptable conduct than either customary medical practice or the testimony of free-lance medical experts. They might also be less limiting to practitioners and more tolerant of responsible economizing than a single authoritative guideline might be.

Although practice guidelines produced under the conventional, more monolithic approach to guideline making would often state ranges of defensible practices, those standards, developed largely by broad-based professional organizations, would not represent society's considered judgment on the many complex issues. Moreover, making such guidelines the exclusive standard for establishing liability would limit the freedom of society's agents-courts and juries-to look at all the circumstances of a case and to take account of nontechnical considerations. On the other hand, if a variety of reputable guidelines existed expressing different views, either of the suggested alternative legal tests-but especially the test evaluating care for reasonableness and prudence under societal rather than merely professional standards-might provide a better quality of justice, and better signals to professionals of society's expectations, than a legal system that simply implements the medical profession's official pronouncements. In such a pluralistic environment, physicians concerned about being forced to practice cookbook medicine should find either of these legal formulations of their duties more respectful of their status as professionals with personal responsibilities to individual patients than a single set of more or less mandatory guidelines would be. Unfortunately, however, in the area of medical care, the law has always tended to be more regulatory than this. If provided with authoritative practice guidelines as a source of regulatory standards, it is likely to remain so-however the test for physician negligence is formulated.

\section{Legislating Immunity for Care Complying with Guidelines}

While any injury-causing violation of a practice guideline is very likely to be treated by a jury as negligence per se even if it is not regarded as such in law, the situation is not symmetrical: Compliance with a guideline would not be as likely to insulate a physician from liability. Thus, a plaintiff who could not show a guideline violation would probably still be entitled to have his case submitted to a jury if he could offer credible evidence that the guideline was too general to define appropriate care in the particular case, that custom required doing more than the minimum contemplated by the guideline, or that the guideline minimum was itself a negligent standard. Because juries may be swayed by sympathy for the plaintiff or by distrust of physicians and their possibly self-serving standards, a finding of liability might result even if the physician acted in reasonable reliance on a guideline. 
Such asymmetry in the practical impact of practice guidelines in litigation-giving plaintiffs more help in proving negligence than defendants receive in proving due care-might lead physician groups and others to seek legislation directing courts to treat practice guidelines not merely as evidence - of the standard of care but as the standard itself. Such legislation might stop short of making violations of practice guidelines negligence per se but still declare that compliance with a guideline is a complete defense. ${ }^{48}$ Earlier federal legislation that was designed to accomplish a similar purpose was not so categorical, however, and thus failed to give physicians any meaningful protection. That legislation provided that actions taken "in compliance with or in reliance upon professionally developed norms of care and treatment applied by [a statutorily designated Peer Review Organization ("PRO")]" would be immune from challenge in a civil suit, but only if the physician "exercised due care in all professional conduct" related to such actions. ${ }^{49}$ Whether because the latter clause canceled the former one or because PROs did not develop norms as precise and prescriptive as practice guidelines are expected to be, this immunity provision has been essentially inoperative. ${ }^{50}$ At a minimum, any legislative attempt to immunize physicians for compliance with professional standards would probably have to limit the inquiry on the due care issue to whether the guideline applied and was complied with. ${ }^{51}$

Would such legislation be a good idea? Many physicians would object to it despite the marginal protection it might provide them, on the ground that it subjects the medical profession to "cookbook medicine" and devalues the element of judgment in treating particular patients. They might also argue that, because a plaintiff could almost always allege that a guideline was inapplicable to the particular case because of some circumstance not contemplated by the guideline makers, the profession would gain little protection from surrendering its members' professional freedom. ${ }^{52}$ Plaintiffs' lawyers would argue against making guidelines conclusive evidence of the standard of care on the grounds that they would usually be too general to resolve specific cases and might not reflect the advancing state of the art and medical custom.

Because compliance with an authoritative practice guideline would certainly impress a jury even if it did not conclusively resolve the issue in the case, it may be that no statutory immunity that was qualified enough to take

48. Legislation to this effect was recently adopted, on an experimental basis, in the State of Maine. See note 16 . Indeed, although compliance with the guidelines provided for would be a complete defense, the guidelines were expressly made inadmissible to establish negligence. " $|\mathrm{O}| \mathrm{nly}$ the physician or the physician's employer may introduce into evidence as an affirmative defense the existence of the practice parameters and risk management protocols developed pursuant to [the project]." 1990 Maine Pub Laws ch 931 \& 2975(1) (West, 1990).

49. 42 USC $\$ 1320 c-6$ (c) (1983).

50. No cases are cited in the annotation in 42 USC.A $\$ 1320$ c-6 (1983 \& Supp). No cases were located pursuant to a Westlaw computer search (May 7,1991 ).

51. There would also be the additional questions whether the physician exercised appropriate skill and obtained informed consent.

52. The recent Maine legislation, see notes 16,48 , attempts to maximize the protective benefits of guidelines while eliminating the mandate to conform. 
account of the inevitable shortcomings of guidelines as actual rules for medical practice could significantly improve the current situation. Like the immunity provision of the PRO law, any such enactment would make little practical difference in the conduct of lawsuits or the practice of medicine. The problem of defensive medicine could probably be addressed as effectively by good guidelines alone as by a statutory provision declaring that practitioners are never required to go beyond the guidelines in caring for an individual patient.

An even stronger argument against a statutory provision obligating a physician only to comply with applicable practice guidelines is that such a provision requires officially singling out one set of guidelines and giving it the effect of public policy. Although the guidelines movement in the medical profession and the federal guidelines program itself are both open to the interpretation that a single set of guidelines should set the exclusive standard of acceptable medical practice, federal legislation does not explicitly embrace this one-right-way philosophy. Indeed, Congress was probably reluctant, at least for the sake of appearances, to convert private guidelines explicitly into public regulatory prescriptions. As a consequence, there is still a clear opportunity for administering the federal guidelines program pluralistically, inviting any organization that can satisfy the program's criteria and standards for guideline development to have its particular protocols and operating procedures certified by the program's panels. ${ }^{53}$ As discussed further below, encouraging the development of practice guidelines in this spirit could make medical care responsive to consumer choice in a way it has never been before.

A world featuring a multiplicity of inconsistent practice guidelines would present even more uncertainties for physicians than one in which even complete compliance with the dominant guidelines did not guarantee immunity from malpractice liability. But these uncertainties would be largely dispelled if one set of guidelines were known to govern a particular doctor/patient relationship. In theory, at least, physicians and patients are free to select one set of guidelines and incorporate them by reference in a contract for professional services. Although there may be some difficulties in getting courts to recognize such contracts, they have much to offer to both parties. The next section of this article examines the uses and enforceability of such contracts more fully. For the moment, it can be observed that they are attractive as a way of providing physicians with clear statements of their obligations to particular patients without legislation effectively subjecting all physicians and all patients to the same possibly inappropriate standards.

53. See Havighurst, 34 St Louis U L J at 804-16 (cited in note 1). 
IV

\section{Practice Guidelines in Private Contracts-A Deregulatory Agenda}

Although most observers view practice guidelines as a way of improving the tort system as a regulatory program, better regulation may not be what the public needs most. It is also possible to view the guidelines movement as an opportunity for deregulation of a sort. It is not inevitable, after all, that the tort system must operate as regulation, subjecting all physicians to centrally developed, prescriptive norms. Instead of defining the obligations of health professionals in universal terms, the law might contemplate that the physician's duty in a given malpractice case might be found in the contract between the physician and the patient. ${ }^{54}$ If the physician/patient contract is not specific as to the physician's duties, then the norms and standards of the profession as a whole should be read into the agreement by implication. But if the parties can fairly be said to have chosen a different regime of responsibilities and rights, courts might then foreswear their customary regulatory stance and allow the parties' choices to control. Although this counsel may have been impractical in the past, the practice guidelines movement opens up deregulatory possibilities that did not previously exist.

If developed pluralistically, practice guidelines could facilitate both the rational exercise of consumer choice and the writing of contracts that specify just what health services insured groups of consumers do and do not wish to purchase on a prepaid basis. Public programs, too, could incorporate selected guidelines as a way of putting limited resources to their best uses. To the extent that the regulatory character of professional norms and standards in the US health care system is attributable to the practical difficulty of defining and giving legal effect to any alternative standard of care, practice guidelines offer an excellent opportunity-possibly the last clear chance-to deregulate the health care field. With their great potential for enabling decentralized decision making on medical issues, the availability of competing practice guidelines could finally allow the market for health services to allocate society's resources in accordance with cost-conscious consumer preferences. 55

\section{A. Completing the Deregulation of the Health Care Sector}

Privately financed health care experienced some deregulation in the late 1970 s and early 1980 s as government shifted its primary attention to the control of costs in its own programs and left private purchasers to fend for themselves in cost containment and otherwise. ${ }^{56}$ As intended, this change in federal policy triggered significant innovation in health care delivery and

54. The terms of this contract might be found in the arrangement between the patient and an organized health plan with which the physician is affiliated in some capacity.

55. See generally Havighurst, 34 St Louis U L J 777 (cited in note 1).

56. See generally Havighurst, $11 \mathrm{~J}$ Health Pol, Pol'y \& Law 697 (cited in note 22). 
financing. In many people's judgment, however, the policy of relying less on government regulation and more on market forces failed to have the desired effect of controlling costs. ${ }^{57}$ Nevertheless, introducing new forms of price competition and new incentives for consumers to patronize lower-cost preferred providers did lower some unit prices and allow the implementation of some managed-care techniques. Once the gains from these one-time reforms were realized, however, the cost trend resumed its upward course, leaving employers and consumers still frustrated by their inability to impose their own priorities on a system that makes its own rules for how their dollars are spent. The new cost-containment tools that became available to purchasers in the $1980 \mathrm{~s}$, while somewhat effective, are still not capable of controlling utilization of services to the optimal extent. ${ }^{58}$ Additional tools are needed.

One reason (there are many others ${ }^{59}$ ) why health care costs have continued to rise despite increased reliance on competition and consumer choice in the health care field is that purchasers-government, employers, and other payers-have not, as a practical matter, been free to economize even where it would be in the consumer's interest to do so. Instead, they find themselves obliged to pay for nearly everything that the health care industry chooses to produce-from specific services that physicians prescribe in good faith to whole new technologies that the medical profession identifies as efficacious. Even where a payer senses that a particular service yields only minor incremental benefits, it is still likely to be legally obligated to pay for it unless it can carry the burden of proving that the care was inappropriate under professional norms. ${ }^{60}$ Similarly, physicians, even when they are inclined to economize, are hampered in so doing by the threat that a malpractice suit would be brought, and possibly won, if omission of some test, some treatment, or some precaution were to be followed by a bad medical result. In short, payers, physicians, and consumers face a legal environment

57. See, for example, William Schwartz, The Inevitable Failure of Current Cost-Containment Strategies: Why They Can Provide Only Temporary Relief, 257 J Am Med Ass'n 220 (1987).

58. Innovations in managed care and utilization review may have been helpful in obtaining better compliance with professional norms and in promoting economizing within such norms. But care managers and utilization reviewers have no legal or clear contractual warrant for denying patients coverage for any care that can be characterized as medically necessary. See note 20 . On the other hand, they may induce some physicians to economize by threatening, justifiably or not, to withhold payment for particular services or by other means. Although their methods are open to legal question, they may still succeed because physicians and patients cannot afford to contest every debatable decision. In addition, utilization managers typically refuse to disclose their screening methods and payment policies so that physicians cannot outsmart the reviewers. Everyone would be better served and on safer legal ground, it would seem, if the rules were scientifically developed, spelled out and agreed to in advance, and then administered in an open manner as contractual limits on the obligations of both payers and providers.

59. The most obvious culprits are the aging of the population and advances in medical technology.

60. See generally Havighurst, Decentralizing Decision .Making at 22. 23-25 (cited in note 22). The Medicare program is committed to pay for all care that is "reasonable and necessary," 42 USC $\$ 1320 c-3(a)(1)(A)$ (1983), a standard that necessarily incorporates professional norms. Private health insurance also generally undertakes to cover all care that meets professional standards of medical necessity. See note 19. 
in which many of the most promising economizing moves are simply not available to them as a practical matter.

An underappreciated difficulty encountered by would-be economizers in the purchasing of health services is the practical impossibility of writing private contracts that specify precisely what the payer, or the physician, is or is not obligated to do in every medical situation that might be encountered. For such contracts to be useful in limiting payer/provider obligations and patient entitlements, they would have to be extraordinarily detailed. Indeed, they would have to be the equivalent of a medical textbook that not only prescribes for all medical exigencies but also reflects in each prescription the particular preferences and circumstances of the parties. Because it has not been feasible to specify in advance precisely what the consumer expects his health plan to pay for or what he desires to purchase from providers, drafters of insurance policies and other contracts for medical care have had to formulate patients' entitlements and payers' and physicians' obligations in terms that implicitly incorporate professional norms and standards. Although writing a contract to cover only "medically necessary" or only "appropriate" care is efficient in comparison with any available alternative, ${ }^{61}$ such formulations incorporate professional norms, which implicitly attach high values to medical services. Thus, the prohibitive transaction (contracting) costs of specifying alternative rights and obligations have hampered corporate middlemen-employers, insurers, and organized health plans of all kinds-in designing and marketing packages of medical services that are customized to appeal to different customers' preferences and pocketbooks. Public programs, too, have lacked the ability to specify their coverage without reference to professional norms. ${ }^{62}$

Private economizing has been further inhibited by the legal system's complete failure to take account of the difficulty of writing contracts that place effective limits on a physician's or a payer's obligations. Instead, courts have viewed insurance policies and contracts for medical services as contracts of adhesion or have routinely construed them against the more powerful party, which was also responsible for the drafting. ${ }^{63}$ In some instances they have ignored or construed away explicit exclusions so as not to disappoint the "reasonable expectations" of the insured.64 In addition, courts threaten an insurer or other health plan with liability for punitive damages if jurors conclude that it insisted in "bad faith" on a narrow interpretation of its

61. See notes 19, 60; Richard Epstein, Medical Malpractice, Imperfect Information, and the Contractual Foundation for Medical Services, 49 L \& Contemp Probs 201, 207 (Spring 1986); Clark Havighurst, Altering the Applicable Standard of Care, 49 L \& Contemp Probs at 265, 266-72 (Spring 1986).

62. An effort in the State of Oregon to define priorities in medical care for the purpose of allocating a limited state Medicaid budget to its best uses has attracted a great deal of interest and is the nearest approach anywhere to using something resembling practice guidelines to escape the necessity of paying for all care meeting the criterion of medical necessity. See generally Special Report, National Debate Sparked by State Plan to Expand Access to Heallh Coverage, 17 Pens Rep 725 (BNA, April 30, 1990)

63. See generally Havighurst, Decentralizing Decision Making at 38-41 (cited in note 22).

64. See Kenneth Abraham, Judge-Made Law and Judge-Made Insurance: Honoring the Reasonable Expectations of the Insured, 67 Va L Rev 1151, 1151.52 (1981). 
contractual obligations. ${ }^{65}$ In these circumstances, payers have been in a poor position to protect the common funds to which their subscribers contribute and to enforce even modest limitations to which their subscribers have mutually agreed. Tending to view each dispute over payment as pitting a weak consumer against a corporate deep pocket and their task as the regulatory one of enforcing societal standards, courts have failed to recognize the collective stake that consumers have in exercising freedom of contract.

Similarly, courts in malpractice cases have rarely recognized any contractual limitation on the legal duty of professionals to provide care that meets conventional standards or on patients' right to sue in tort for breaches of that duty. One court, for example, refused, on public policy grounds, to give effect to an exculpatory clause signed by a patient patronizing a low-cost university dental clinic. ${ }^{66}$ Pure exculpatory clauses of this kind, under which health care providers seek to escape all responsibility for legally defined negligence, are especially vulnerable to invalidation. But most lawyers would counsel that any contract altering a patient's substantive tort rights is also unlikely to be enforced. Although courts have often upheld private agreements to arbitrate future malpractice claims, such contracts change only the forum in which claims are resolved, not any substantive right. ${ }^{67}$ Moreover, the skepticism encountered even in these cases, together with the hostility of many courts toward legislative changes in patients' tort rights, supports the judgment that attempts to alter tort rules by private contract would face heavy going in litigation. Indeed, the entire legal culture has responded quite coolly to academic proposals that parties be allowed to adopt voluntarily, by private contract, the same kind of limits that some states have mandated for all patients in tort-reform legislation. ${ }^{68}$ There are few areas of the law where the institution of private contract seems quite as dead as it is in the area of medical services, where the legal system, drawing its standards unquestioningly from the medical profession, deems the rights it has created to be virtually unalienable. 69

The legal system's tendency to define the obligations of both payers and providers by referring, not to their contracts, but to professional norms and standards amounts to a kind of regulation of the terms of dealing. Because this regulation is not statutory, however, but is built into the legal culture, the industry's cost problems are seldom attributed to overregulation amenable to legislative reform. Yet the practical effect of disabling the institution of private contract in the purchasing of medical services and health care financing is to deny to consumers (just as explicit regulation might do) the

65. For example, Taylor $v$ Prudential Ins. Co., 775 F2d 1457, 1458-59 (1 lth Cir 1985).

66. Emory University v Porubiansky, 248 Ga 391, 394, 282 SE2d 903, 905 (1981).

67. See Madden v Kaiser Foundation Hospitals, 17 Cal 3d 699, 71 1, 131 Cal Rptr 882, 890, 552 P2d 1178,1186 (1976) (stressing that "[the arbitration clause] does not detract from Kaiser's duty to use reasonable care in treating patients...").

68. See note 39.

69. See Clark Havighurst, Private Reform of Tort-Law Dogma: Market Opportunities and Legal Obstacles 49 L \& Contemp Probs at 143, 163-72 (Spring 1986). 
opportunity to purchase anything except variants of a single, extravagantly costly product-state-of-the-art medical care. If the crucial feature of regulation is the centralization of decision making and the foreclosure of consumer choice, then private health care is still a heavily regulated industry. One reason why it is not so perceived is that the overregulation noted does not affect providers of care adversely, ${ }^{70}$ infringing only the freedom of consumers to economize by purchasing something other than Mercedes-style health care. Nevertheless, the effects of overregulation-overspending on the regulated activity and transfer of wealth from consumers to providers of the regulated service-closely resemble the effects of the regulatory regimes that were the subject of second thoughts in the deregulation movements of the 1970 s and 1980s. ${ }^{71}$

Rationing medical care is an extraordinarily difficult task, whether undertaken through direct government controls or through private institutions. In the private sector, however, there is at least some opportunity for placing the responsibility for difficult decisions in the hands of individuals and groups who are in a position to enjoy the tangible benefits of economizing and to weigh them against possible future consequences. Relying on private choices (which government can and should subsidize to prevent undue hardship and which can be exercised collectively or through agents to overcome information problems) could relieve both government and the medical profession of the responsibility for saying "no" on benefit/cost grounds to potentially beneficial health care that individual patients wish to receive and physicians wish to provide. Even where private economizing decisions are made by agents rather than by the affected individuals themselves, there is some direct accountability for both the cost and quality of care and a greater identity of interests than is usually recognized. ${ }^{72}$ On the other hand, public regulators charged with rationing medical care are often in a position to take public and political credit for the apparent benefits of liberality without having to account for its hidden costs. Judges and juries are in a similar position, able to do good for individual plaintiffs without recognizing the cost that their liberality imposes on the

70. Indeed, the regulatory regime identified here raises provider incomes by effectively shielding providers from privately imposed cost controls. Consumer advocates, concerned only about raising standards and extending regulation, are unlikely to perceive, much less to protest, that the medical profession and the legal system, working in tandem, have systematically denied consumers economizing opportunities. Such is the force of the professional paradigm of medical care even among those who view themselves as the profession's political opponents. See generally Havighurst, 30 Jurimetrics J 415 (cited in note 12); see also note 22.

71. See, for example, Roger Noll, Reforming Regulation: An Evaluation of the Ash Council Proposals (Brookings Institution, 1971). For discussions of how overt economic regulation of the health care sector, undertaken ostensibly to achieve cost containment, invites similarly perverse consequences and benefits dominant interests in the industry, see Sallyanne Payton \& Rhoda Powsner, Regulation Through the Looking Glass: Hospitals, Blue Cross, and Certificate-of-Need, 79 Mich L Rev 203 (1980); Clark Havighurst, Regulation of Health Facilities and Senices by "Certificate of Need," 59 Va L Rev 1143 (1973).

72. See FTC "Indiana Fed'n of Dentists. 476 US 447, 463 (1986) (observing that, because of competition, insurers "must satisty their potential customers" with respect to both cost and quality). 
economy as a whole and, specifically, on the class of consumers to which the plaintiff typically belongs.

Just as the legal system's hesitancy to enforce certain provisions in private health care contracts can be equated with public regulation, private contracting can be viewed as a potentially promising vehicle for deregulating the health care industry, decentralizing decision making on the most sensitive and difficult issues. To embrace this vision is not to denigrate the ideals of fairness and equal entitlements to medical care that motivate the legal system to question the legitimacy of contractual economizing. ${ }^{73}$ Nevertheless, without public financing to support these ideals, the legal system only distorts the market for medical care when it refuses to recognize that consumers might have good reason for economizing in purchasing health services. ${ }^{74}$ One consequence of the legal system's effort to prevent individual hardship by positing an entitlement to medical care of uniformly high quality has been the unavailability of low-cost health insurance that covers truly essential care but excludes services whose benefits are of only limited value in relation to their costs. Without such low-cost options-such as the market routinely offers with respect to other goods and services-some thirty-seven million Americans, many of them gainfully employed, have had to go without any health insurance. Many more consumers have been forced to devote a much greater proportion of their income to health care than they would choose to devote if they were allowed a choice. By imposing a compulsory regulatory regime and limiting freedom of contract, the legal system has precluded developments that would have ameliorated some of the health care industry's most serious problems.

\section{B. Guidelines as the Final Piece of the Puzzle}

Against this background, practice guidelines can be seen as a potential vehicle for finally enfranchising consumers to choose the style of medical care that best suits their preferences and pocketbooks. Such a deregulatory outcome would be possible, however, only if the guidelines movement evolves pluralistically and yields a range of meaningful, well-considered options among which government, private payers, physicians, and consumers can choose in establishing health care plans and doctor/patient relationships. The multiplicity of guidelines developed in a pluralistic environment would reflect not only differing assessments of the scientific evidence but also differing conclusions on the many trade-offs between benefits and costs. Although some guidelines would emanate from broad-based professional

73. Compare Haavi Morreim, Cost Constraints as a Malpractice Defense, Hastings Center Rep 5, 8 (February-March 1988):

[A] formal legal concession to cost constraints is tantamount to denying that the poor are entitled to fair remedy for equivalent malpractice injuries. The same injury could represent a tort for a wealthy person, yet not a tort for an indigent patient .... Such an outcome would surely offend our society's egalitarian values.

See also Haavi Morreim, Cost Containment and the Standard of Medical Care, 75 Cal L Rev 1719 (1987).

74. See Havighurst, 34 St Louis U L J at 802-04 (cited in note 1). 
bodies, other groups and organizations might also contribute to the movement, including individual managed-care plans writing rules for their own internal use. Guidelines developed in a climate that was hospitable to decentralized decision making could be more precise and prescriptive on debatable points than guidelines intended for universal application. Instead of stating ranges of acceptable practice, such guidelines could take the form of actual protocols, specifying the normal course of treatment while leaving room for departures in unusual cases.

The availability of practice guidelines from a variety of reputable sources would dramatically reduce the main practical obstacle to effective consumer choice in medical care-the prohibitive cost of specifying anything other than professional standards. ${ }^{75}$ Private health care plans, by incorporating carefully selected guidelines in their contracts with patients on the one hand and providers on the other, would be able to supply practice standards customized to the particular needs of potential subscribers. Competition to supply the best value for various levels of investment would empower consumers finally to write their own tickets in prospectively ordering medical services. Public programs, too, could adopt guidelines that economize responsibly in those ranges where the benefit of additional medical care is not clearly worth the added cost.

Despite the powerful centralizing forces supplied by the professional and political models of medical decision making, the practice guidelines movement, as currently constituted, may still evolve pluralistically. The chances for decentralization and deregulation would be immeasurably increased, however, if the federal Forum for Quality and Effectiveness in Health Care were explicitly operated, not with a view to promulgating definitive guidelines for universal use, but as a public certification program. ${ }^{76}$

75. For a somewhat different but almost equally effective strategy for facilitating the making and specification of choices, see note 76 .

76. This proposal is elaborated in Havighurst, 34 St Louis U L J at 804-16 (cited in note 1), which also approves, as a second-best strategy, a policy of developing authoritative guidelines for general use but expressly requiring that they set forth several alternative formulations of the standard of care that could be readily incorporated as protocols in public or private health plans. Id at 816. In contrast to the professional and some payers' models of practice guidelines (see notes 17 . 19), some guideline makers have contemplated guidelines that would allow decision makers to select different standards based on cost considerations. For example, Brook, $262 \mathrm{~J}$ Am Med Ass'n at 3030 (cited in note 1) ("[T]he cost implications of adopting the guidelines would be considered. Adherence to some guidelines, even if that adherence improves outcomes, may not be worth the cost, and this information will need to be produced along with the guidelines."). The methodology developed by Dr. Brook and his colleagues at RAND provides for expressly scoring medical procedures for relative appropriateness in each of many carefully defined clinical conditions. and the resulting rankings could presumably be adapted to meet the contracting needs of private and public health plans. Indeed. RAND methodology is already being used in managed-care contexts by Value Health Sciences, Inc.

Although there may be political and other reasons why pluralism is more likely to be pursued, if at all, by requiring definitive guidelines that facilitate choice rather than by inviling guidelines from multiple sources, this writer would still hold out for the strategy recommended in the text. The main reason is that it will take very long to come up with definitive guidelines that meet the RAND ideal in every area of medical practice. Instead of waiting for the ideal to be realized. the federal guidelines program could start the ball rolling rapidly in the direction of pluralism by proceeding as suggested in the text, while retaining the RAND ideal as its ultimate objective. Indeed, increasing use of 
So conceived, the federal program would grant official recognition to any set of guidelines that meets minimum requirements with respect to development procedure, form, and the use of scientific evidence; guidelines would be recognized without regard to their consistency with other guidelines that the Forum's oversight panels may also have approved. There is nothing in the federal guidelines legislation that precludes adoption of such a pluralistic approach to guideline development and use. Only the firmly entrenched professional and political models of practice guidelines, with their common regulatory premise, stand in the way of administering the guidelines program as an aid to pluralism and consumer choice.

Federally sponsored outcomes and effectiveness research, coupled with certification of responsible guidelines by publicly selected panels of experts, might in time realize the full potential of informed consumer choice in the purchasing of medical care. Until the federal program achieves this ultimate objective, however, the federal panels could usefully screen the large number of existing guidelines to identify the better ones and certify them for possible use in public or private health plans. The Forum could also sponsor independent guideline initiatives to supplement profession-sponsored efforts and could invite organized health plans and managed-care organizations to submit internally developed protocols for possible approval in contemplation of their explicit incorporation in contracts. ${ }^{77}$ Although applying only minimal criteria and standards to guidelines at the outset, the federal program could periodically raise its level of expectation as the scientific base becomes firmer and as the art of guideline making improves under the program's prodding. ${ }^{\mathbf{7 8}}$ Administered as a certification program, the federal guidelines effort could immediately provide valuable consumer protection, expand options, and begin to lay the groundwork for finally decentralizing crucial choices. With adequate investment and wise leadership, the program could eventually revolutionize the market for medical care as well as medical practice itself.

Earlier discussion noted the benefits to the tort system that could be expected from introducing practice guidelines. These benefits would not be lost under pluralism. Guidelines emanating from the dominant medical specialty societies would presumably supply the legal standard of care in all cases where no alternative standard of care was specified, thus improving the clarity and predictability of the law's requirements. These same goals would be achieved to an even greater degree, however, in cases where specific guidelines had been made applicable by express agreement. ${ }^{79}$ In the absence

guidelines falling short of that ideal could be expected to stimulate government, professional organizations, and other elements in the private sector to work harder and spend more to come up with superior ones, thus achieving the ultimate objective sooner than would be likely under a more conservative, controlled approach.

77. On the current tendency to keep utilization management criteria secret and noncontractual, see note 58.

78. Periodic recertification should be required to ensure that guidelines are appropriately updated and continue to reflect the state of the guideline-development art.

79. Malpractice litigation under a preselected set of practice guidelines would usually be simpler than under general professional standards. Expert witnesses would no longer be asked to testify to 
of an agreement on a specific standard, there would remain the issue, considered earlier, of how courts in malpractice cases might regard practice guidelines that neither reflect nor dictate customary practice. Presumably courts would be more receptive to alternative guidelines as evidence of acceptable minority practice if the federal guidelines program had made pluralism more respectable by proceeding as suggested above.

In the absence of public certification of practice guidelines, most courts would probably adhere to their previous paternalism, refusing almost automatically to enforce contractual provisions that purported to employ guidelines to limit the rights of patients and the obligations of providers. On the other hand, if federally convened panels had verified that a particular set of guidelines had a scientific basis and rationally addressed the trade-offs encountered, courts should feel relieved of most of their responsibility for consumer protection. In addition, the potential of such guidelines to simplify the administration of malpractice cases should also induce courts to give up their traditional role of trying to deduce, from inadequate evidence, the professional standard of medical care that should be applied in each case. Liability insurers would then be able to employ guidelines in making quicker, more accurate judgments on the validity of particular claims.

Precisely because the regulatory regime currently governing the medical care system is nonstatutory and based largely on judges' sense of the disadvantages of consumers in the medical marketplace, deregulation could be best facilitated by a federal effort to reduce those disadvantages and give greater reliability and credibility to consumers' economizing choices. The legal system has no explicit mandate to judge physician performance only by the norms and standards of the medical profession. The appearance of a credible alternative source of standards could thus cause the courts rather quickly to recognize the legitimacy of consumer decisions to accept a style of medical care different from the costly one that the medical profession collectively prefers.

\section{$\mathrm{V}$ \\ Conclusion}

This article finds no reason to doubt the conventional expectation that the administration of the law of medical malpractice as a program of qualityassurance regulation will improve substantially as medical standards are increasingly codified in practice guidelines. The main message of this article, however, is that medical practice is overregulated, not just badly regulated, by tort law. Thus, the article takes issue with the view that the tort system's primary need is a better benchmark for evaluating a physician's actions than

\footnotetext{
the standard of care but would be asked only if the practitioner complied with the prescribed explicit standard. In many instances, it would be necessary to interpolate a standard for the particular case from the written standards, but such standards would usually be more specific and helpfully prescriptive than guidelines intended for general use. Although there always would be factual questions and issues with respect to causation and whether an appropriate degree of skill was demonstrated, juries would have less discretion than they have today.
} 
customary medical practice, the law's current source of standards. The main argument herein is that the development of practice guidelines should be fostered with a deregulatory, decentralizing objective in mind, in order that the health care system in general and malpractice law in particular can move out of their traditional command-and-control mode.

This article proposes that, contrary to the views of most physicians and most policy makers, practice guidelines should be allowed to evolve in a pluralistic fashion. In addition to providing financial support for outcomes and effectiveness research, the federal government should operate its new Forum for Quality and Effectiveness in Health Care as a certification program, identifying for the benefit of consumers and others those guidelines that are responsibly developed using the available scientific evidence and due care in appraising and comparing benefits and costs. ${ }^{80}$ Although the development of a full spectrum of competing guidelines meeting high standards would obviously take some years, public and private purchasers of medical care could rather quickly be given opportunities to choose among a multiplicity of guidelines meeting minimal standards of reliability. With such guidelines available, purchasers of medical care would no longer be forced by circumstances-especially the prohibitive transaction costs of specifying an alternative standard of care-to purchase only care that meets the norms and standards of the medical profession. Instead, purchasers would find it increasingly feasible to specify standards of their own choosing. By incorporating particular guidelines by reference in their various contracts, private health care plans could offer consumer groups, for the first time, a chance to give effect to their own preferences and circumstances in prospectively ordering medical care. Public programs, too, could impose well-considered limits on the entitlements they create, allowing them to provide essential services to more beneficiaries at the same cost they now incur in providing state-of-the-art care to limited populations. The new availability of low-cost options in the marketplace would also allow many of the uninsured working poor to purchase basic health coverage.

Courts administering the law of medical malpractice could assist in carrying out this deregulatory scenario by recognizing specific guidelines incorporated in private contracts or public financing schemes as the standard of care that, to the extent applicable, should govern in litigation challenging a physician's performance. On the other hand, malpractice courts could continue to frustrate decentralization of decision making by clinging to the fiction that they and the medical profession are jointly charged with defining the standard of medical care that is optimal for the American people. This article has suggested that the federal program to develop practice guidelines is fully capable, if well managed and well funded, of providing essential consumer protection without stifling-and indeed laying a solid foundation for-intelligent consumer choice.

80. For an alternative, though less immediately effective way of achieving the desired pluralistic result, see note 76 . 
